\title{
Brinzolamide-timolol suspension: acceptability and side effect profile
}

This article was published in the following Dove Press journal:

Clinical Ophthalmology

30 March 20II

Number of times this article has been viewed

\section{Doherty \\ SG Fraser \\ PS Phelan}

Sunderland Eye Infirmary, Sunderland, Tyne and Wear, UK
Correspondence: Mark Doherty Department of Ophthalmology Royal Victoria Infirmary, Queen Victoria Road, Newcastle upon Tyne, NEI 4LP, UK Tel +44 I9| 2336161

Fax +44 I9| 221205I

Email highburymark@yahoo.co.uk
Background: This study aimed to determine the frequency, nature, and impact of side effects associated with the use of brinzolamide-timolol suspension, a topical ocular antihypertensive preparation.

Methods: A questionnaire was distributed to 76 consecutive patients attending the Sunderland Eye Infirmary Glaucoma Service who were using the brinzolamide-timolol suspension. The questions related specifically to effects on daily life, blurring of vision, stinging, irritation, and acceptability compared with any drops previously used. Respondents were asked to grade their answers to these questions using a numerical scale from 0 to 10 .

Results: Seventy-six patients (100\%) responded, comprising 58 females and 18 males, aged 68-95 years, treated for 3-7 months. Quality of life was not significantly affected, with the majority of patients recording a response between 0 and 2 . Visual blurring was a more prominent feature, with the most common scores being 3 and 4. Stinging did not appear to be a prominent feature, with 0 as the most common response. Similarly, irritation was not a common finding, with most respondents scoring 0 and 1 . Finally, the brinzolamide-timolol suspension compared favorably with previously used drops, with the vast majority of patients expressing a preference for this suspension over other topical medications.

Conclusion: Brinzolamide-timolol suspension appears to be a well tolerated and acceptable medication, with minimal effect on patient quality of life.

Keywords: intraocular pressure, glaucoma, quality of life, side effects

\section{Introduction}

Glaucoma is a significant cause of visual loss worldwide. Elevated intraocular pressure is the only modifiable therapeutic risk factor for glaucoma-associated optic neuropathy. ${ }^{1}$ Pharmacologic reduction of elevated intraocular pressure is often associated with a slowing of progressive glaucomatous optic neuropathy and consequent visual loss. ${ }^{2}$

When first-line medical treatment is deemed to be inadequate, a fixed combination of a beta-blocker with either a prostaglandin analog or a carbonic anhydrase inhibitor is often used. The advantages of fixed combination products over separate instillation of their constituents are well recognized. ${ }^{1-3}$ These include avoidance of washout (whereby inadequate time is allowed between separate instillations, leading to suboptimal drug absorption), reduced exposure to preservatives, reduced cost, and increased convenience, with subsequent improvement in patient adherence to treatment.

Azarga $^{\mathrm{TM}}$ (Alcon Laboratories Inc, Fort Worth, TX) is a fixed combination of brinzolamide, a carbonic anhydrase inhibitor, and timolol, a beta-blocker. It is a 
suspension with a $\mathrm{pH}$ of 7.2 and preserved with benzalkonium chloride $0.10 \mathrm{mg} / \mathrm{mL}$. The concentration of brinzolamide is $1 \%(10 \mathrm{mg} / \mathrm{mL})$ and that of timolol is $0.5 \%(5 \mathrm{mg} / \mathrm{mL}){ }^{1}$ The combination has been demonstrated to lower intraocular pressure more effectively than either timolol $0.5 \%$ or brinzolamide $1 \%$ alone dosed twice daily, while providing a similar safety profile to that of the individual components. ${ }^{3}$ Published data also show that fixed combinations of brinzolamide $1 \%+$ timolol $0.5 \%$ and dorzolamide $2 \%+$ timolol $0.5 \%$ have similar efficacy for lowering intraocular pressure. $^{2,3}$

Compliance is a key issue in the treatment of glaucoma, and a course of therapy that is well tolerated by the patient is more likely to be adhered to. ${ }^{4-6}$ The aim of this study was to determine what side effects were experienced by a cohort of patients using the brinzolamide-timolol suspension, and to investigate their impact, if any.

\section{Methods}

The study was conducted at the Glaucoma Unit in the Sunderland Eye Infirmary, Sunderland, UK. A questionnaire was prepared, consisting of five questions pertaining to the use of brinzolamide-timolol suspension from the patient's perspective (see Figure 1). Each question was assigned a numerical scale from 1 to 9 , with a verbal option at the minimum and maximum of the scale. The questionnaires were distributed by one investigator (PSP) to 76 consecutive patients using topical brinzolamide-timolol suspension. Each patient was handed a questionnaire prior to entering the consulting room and given adequate time to complete their responses.

\section{Results}

Seventy-six consecutive patients completed the questionnaire, ie, 58 females and 18 males, aged 68-95 years. The treatment duration range was 3-7 months. Their responses to the questions are shown in Figure 2.

\section{Discussion}

The clinical efficacy of brinzolamide-timolol suspension was well demonstrated. The fixed combination was found to produce statistically significant and more clinically relevant reductions in intraocular pressure from baseline than brinzolamide $1 \%$ or timolol $0.5 \%$ over six months of therapy. Michaud and Friren demonstrated that brinzolamide 1\% twice daily was equivalent to dorzolamide $2 \%$ twice daily, after treating with timolol $0.5 \%$, in terms of intraocular pressure reduction. ${ }^{8}$ Finally, Manni et al demonstrated that the brinzolamide-timolol combination provides a clinically relevant intraocular pressure reduction in patients with open-angle glaucoma or ocular hypertension that is at least as effective as a dorzolamide-timolol combination. ${ }^{2}$ Given that the brinzolamide-timolol combination has a proven therapeutic effect, our audit aimed to evaluate its acceptability using five different parameters.

1. What effect does your taking Azarga have on your daily life? (minimal answer "no effect"; maximal answer "completely dominates life")

2. To what extent does Azarga cause blurring of your vision? (minimal answer "no effect"; maximal answer "dreadful")

3. How much stinging does Azarga cause? (minimal answer "none"; maximal answer "dreadful")

4. How much irritation does Azarga cause? (minimal answer "none"; maximal answer "very severe")

5. Compared with previous drops how does Azarga compare? (minimal answer "better"; maximal answer "worse")

Figure I Questions in the questionnaire administered to users of brinzolamide-timolol suspension (Azarga ${ }^{\mathrm{TM}}$ ). 
Question 1. What effect does taking Azarga have on your daily life?

\begin{tabular}{|l|c|c|c|c|c|c|c|c|c|c|c|}
\hline Response & "None" & 1 & 2 & 3 & 4 & 5 & 6 & 7 & 8 & 9 & $\begin{array}{c}\text { "Completely } \\
\text { dominates" }\end{array}$ \\
\hline Respondents (n) & 11 & 22 & 20 & 9 & 4 & 2 & 2 & 1 & 0 & 2 & 3 \\
\hline
\end{tabular}

Question 2. To what extent does Azarga cause blurring of your vision?

\begin{tabular}{|l|c|c|c|c|c|c|c|c|c|c|c|}
\hline Response & $\begin{array}{c}\text { "No } \\
\text { effect" }\end{array}$ & 1 & 2 & 3 & 4 & 5 & 6 & 7 & 8 & 9 & "Dreadful" \\
\hline Respondents (n) & 4 & 3 & 8 & 25 & 20 & 5 & 5 & 1 & 0 & 0 & 5 \\
\hline
\end{tabular}

Question 3. How much stinging does Azarga cause?

\begin{tabular}{|l|c|c|c|c|c|c|c|c|c|c|c|}
\hline Response & "None" & 1 & 2 & 3 & 4 & 5 & 6 & 7 & 8 & 9 & "Dreadful" \\
\hline Respondents (n) & 32 & 11 & 9 & 10 & 7 & 5 & 2 & 0 & 0 & 0 & 0 \\
\hline
\end{tabular}

Question 4. How much irritation does Azarga cause?

\begin{tabular}{|l|c|c|c|c|c|c|c|c|c|c|c|}
\hline Response & "None" & 1 & 2 & 3 & 4 & 5 & 6 & 7 & 8 & 9 & "Very severe" \\
\hline Respondents (n) & 27 & 33 & 12 & 4 & 0 & 0 & 0 & 0 & 0 & 0 & 0 \\
\hline
\end{tabular}

Question 5. Compared with previous drops, how does Azarga compare?

\begin{tabular}{|l|c|c|c|c|c|c|c|c|c|c|c|}
\hline Response & "Better" & 1 & 2 & 3 & 4 & 5 & 6 & 7 & 8 & 9 & "Worse" \\
\hline Respondents (n) & 31 & 18 & 18 & 0 & 0 & 8 & 1 & 0 & 0 & 0 & 0 \\
\hline
\end{tabular}

Figure 2 Responses to questionnaire on brinzolamide-timolol suspension (Azarga ${ }^{\mathrm{TM}}$ ) by respondents.

\section{Quality of life}

Our survey showed that, in general, our patients' daily life was not greatly affected by use of brinzolamide-timolol suspension, with the majority of patients who described any effect at all apportioning either 1 or 2 points on the scale.

The relationship between quality of life and use of topical glaucoma medication has been studied previously. Day et al utilized a patient-reported outcome instrument designed to assess patient satisfaction with various attributes associated with topical glaucoma medications, including side effects, and compliance. ${ }^{9}$ Patient satisfaction was statistically correlated with the perceived effectiveness of the medication, ocular irritation, and ease and convenience of use. The authors suggested that patient compliance might diminish as the satisfaction with their medication decreases.
Factors affecting quality of life relating to topical medications can be categorized according to convenience issues and side effects, both ocular and nonocular. The potential benefits of the convenience of a fixed-combination medication have been described above. Ocular side effects are dealt with specifically in the other questions of the survey.

The most common nonocular side effect associated with the use of topical carbonic anhydrase inhibitors is dysgeusia, ie, distortion of the sense of taste. Brinzolamide has been found in a number of studies to cause this side effect. When both medications were used in isolation three times daily, Silver found brinzolamide to cause more dysgeusia than dorzolamide. ${ }^{7}$ Other studies have found both medications to cause this side effect in equal measure, and Manni et al found brinzolamide-timolol and dorzolamide-timolol combinations to cause dysgeusia to a similar degree. ${ }^{2,8,10}$ 


\section{Blurring of vision}

Our survey showed that blurring of vision was a significant side effect amongst those patients surveyed, with more than half of the responders scoring this at either 3 or 4 points on the scale. Visual blurring is a known association of brinzolamide use. ${ }^{3}$ In two independent parallel trials investigating ocular comfort, Silver demonstrated a significantly higher incidence of transient blurred vision in the brinzolamide group compared with the dorzolamide group. ${ }^{4}$ Stewart et al found similar rates of blurring of vision with dorzolamide and brinzolamide treatment. ${ }^{10}$ Studies by Manni et al and Mundorf et al report a higher incidence of blurring of vision with the brinzolamide-timolol combination than with a dorzolamidetimolol combination. ${ }^{2,11}$ Both groups of investigators ascribe this finding to the former being a suspension and the latter being a solution of lower viscosity.

The subjective impact of blurring appears to be variable. In an analysis of eyedrop characteristics, Jampel et al found that, of those patients who attributed a symptom to their drops, blurred vision was the only symptom they were willing to pay more to avoid. ${ }^{12}$ Conversely, Mundorf et al reported that most patients preferred the brinzolamidetimolol combination, despite the higher rate of blurring of vision, suggesting that this effect was less significant than the ocular discomfort experienced with the dorzolamide-timolol combination. ${ }^{11}$

\section{Ocular comfort}

Some studies have considered the symptoms of "stinging", "pain", "irritation", and "burning" together as a group. In two independent multicenter trials, Silver demonstrated that brinzolamide was significantly more comfortable than dorzolamide. ${ }^{4}$ Stewart et al confirmed these findings on initial instillation and after three days of use. ${ }^{10}$ Michaud et al found that brinzolamide produced significantly less ocular burning and stinging than dorzolamide when both were instilled after timolol $0.5 \%{ }^{8}$

Vold et al evaluated the ocular discomfort of brinzolamidetimolol compared with dorzolamide-timolol. ${ }^{13}$ Patients completed assessments based on burning, stinging, heat or warmth, sharp pain, or smarting pain at baseline and after one week of treatment. They found significantly less ocular discomfort with the former than the latter.

\section{Stinging and pain}

Our survey differentiated symptoms of stinging and pain from those of irritation and burning. The majority of respondents in our survey reported none or minimal stinging on instillation of the brinzolamide-timolol combination. This contrasts with numerous data reporting pain on instilling topical dorzolamide. ${ }^{4,714}$ Manni et al reported more pain on instillation of dorzolamide-timolol than instillation of brinzolamide-timolol. ${ }^{2}$ Mundorf et al made a similar observation, and to a greater degree. ${ }^{11}$

It is likely that the acceptability of the brinzolamidetimolol suspension in this regard is due to the relatively neutral $\mathrm{pH}$ of 7.5 for brinzolamide, as compared with a $\mathrm{pH}$ of 5.6 for dorzolamide employed to increase aqueous solubility. ${ }^{1,4,11,13}$ The buffering systems used in the medications may also affect comfort. Dorzolamide-timolol is buffered with sodium citrate, whereas brinzolamide-timolol is formulated without any buffering system. It is also possible that the comfort differences may be explained by intrinsic differences between the two molecules. ${ }^{13}$

\section{Irritation and burning}

As with stinging, irritation did not seem to be a significant factor amongst our respondents, with $36 \%$ of respondents reporting no stinging at all, and $95 \%$ of respondents scoring 0,1 , or 2 points for this symptom. Similarly, Manni et al found that only $2.7 \%$ of patients treated with brinzolamidetimolol complained of irritation, comparing favorably with $10.6 \%$ of patients treated with dorzolamide-timolol. ${ }^{2}$ Mundorf et al made a similar observation. ${ }^{11}$ Comparing brinzolamide-timolol with brinzolamide alone and with timolol alone, Kaback et al specifically elicited symptoms of irritation or burning. ${ }^{3}$ Surprisingly, these authors found that the combination and timolol alone caused more irritation than brinzolamide when used alone.

\section{Comparison with other drops}

In general, the brinzolamide-timolol combination compared favorably with other drops previously used by the patients in our survey. The most obvious medication to compare with brinzolamide-timolol would be dorzolamide-timolol. Three studies have compared these fixed combinations directly. One study specifically found greater patient preference of brinzolamide-timolol over dorzolamide-timolol, ${ }^{11}$ but all studies found the former to be more comfortable than the latter. ${ }^{2,11,14}$

\section{Study limitations}

This type of study may be subject to bias. The questionnaire was administered by the treating clinician in all cases, and it is possible that patients may have felt pressured to report positive outcomes from the medication in question, in order 
to appease the prescribing clinician. Steps were taken to minimize this effect:

- Questions were designed to be objective and unbiased

- Questionnaire was distributed prior to commencement of the consultation, and could therefore not have been influenced by it

- Questionnaire was completed in a private area, separate from the consulting physician and consulting room

Finally, a complete list of previous medications used and total duration of glaucoma for each patient could have been a useful addition to the collected data.

\section{Conclusion}

The patients in our study found the brinzolamide-timolol suspension to be comfortable and acceptable, with little impact on their daily lives. The comfort advantage offered by this suspension has significant implications for improved patient compliance, which could result in more effective control of elevated intraocular pressure. The brinzolamidetimolol suspension has an excellent capability to reduce intraocular pressure and has high patient acceptance, so is becoming an increasingly important therapy for patients with primary open-angle glaucoma or ocular hypertension.

\section{Disclosure}

Editorial and writing and publishing assistance was provided by The Society for Clinical Ophthalmology. These services and the publication fee were paid with an unrestricted grant from Alcon UK Ltd. The views in this article are those of the authors and not necessarily those of Alcon UK Ltd.

\section{References}

1. Beckers HJ, Schouten JS, Webers CA. Role of fixed-combination brinzolamide $1 \% /$ timolol $0.5 \%$ in the treatment of elevated intraocular pressure in open-angle glaucoma and ocular hypertension. Clin Ophthalmol. 2009;3:593-599.

2. Manni G, Denis P, Chew P, et al. The safety and efficacy of brinzolamide $1 \% /$ timolol $0.5 \%$ fixed combination versus dorzolamide $2 \% /$ timolol $0.5 \%$ in patients with open-angle glaucoma or ocular hypertension. J Glaucoma. 2009;18:293-300.
3. Kaback M, Scoper SV, Arzeno G, et al. Intraocular pressure-lowering efficacy of brinzolamide $1 \% /$ timolol $0.5 \%$ fixed combination compared with brinzolamide $1 \%$ and timolol $0.5 \%$. Ophthalmology. 2008;115: 1728-1734.

4. Silver LH. Ocular comfort of brinzolamide $1.0 \%$ ophthalmic suspension compared with dorzolamide $2.0 \%$ ophthalmic solution: Results from two multicenter comfort studies. Brinzolamide Comfort Study Group. Surv Ophthalmol. 2000;44 Suppl 2:S141-S145.

5. Tsai JC, McClure CA, Ramos SE, et al. Compliance barriers in glaucoma: A systematic classification. J Glaucoma. 2003;12:393-398.

6. Kass MA, Gordon M, Morley RE Jr, Meltzer DW, Goldberg JJ. Compliance with topical timolol treatment. Am J Ophthalmol. 1997; 103:188-193.

7. Silver LH. Brinzolamide Primary Therapy Study Group. Clinical efficacy and safety of brinzolamide (Azopt), a new topical carbonic anhydrase inhibitor for primary open-angle glaucoma and ocular hypertension. Am J Ophthalmol. 1998;126:400-408.

8. Michaud JE, Friren B; the International Brinzolamide Adjunctive Study Group. Comparison of topical brinzolamide $1 \%$ and dorzolamide $2 \%$ eye drops given twice daily in addition to timolol $0.5 \%$ in patients with primary open-angle glaucoma or ocular hypertension. Am J Ophthalmol. 2001;132:235-243.

9. Day DG, Sharpe ED, Atkinson MJ, et al. The clinical validity of the treatment satisfaction survey for intraocular pressure in ocular hypertensive and glaucoma patients. Eye. 2006;20:583-590.

10. Stewart WC, Day DG, Stewart JA, et al. Short-term ocular tolerability of dorzolamide $2 \%$ and brinzolamide $1 \%$ vs placebo in primary open-angle glaucoma and ocular hypertension subjects. Eye. 2004;18:905-910.

11. Mundorf TK, Rauchman SH, Williams RD, Notivol R; Brinzolamide/ Timolol Preference Study Group. A patient preference comparison of Azarga (brinzolamide/timolol fixed combination) vs Cosopt (dorzolamide/timolol fixed combination) in patients with open-angle glaucoma or ocular hypertension. Clin Ophthalmol. 2008;2:623-628.

12. Jampel HD, Schwartz GF, Robin AL, et al. Patient preferences for eye drop characteristics: A willingness-to-pay analysis. Arch Ophthalmol. 2003;121:540-546.

13. Vold SD, Evans RM, Stewart RH, Walters T, Mallick S. A one-week comfort study of BID-dosed brinzolamide $1 \% /$ timolol $0.5 \%$ ophthalmic suspension fixed combination compared to BID-dosed dorzolamide 2\%/ timolol $0.5 \%$ ophthalmic solution in patients with open-angle glaucoma or ocular hypertension. J Ocul Pharmacol Ther. 2008;24:601-605.

14. Strahlman E, Tipping R, Vogel R; International Dorzolamide Study Group. A double masked, randomized 1-year study comparing dorzolamide (Trusopt), timolol, and betaxolol. Arch Ophthalmol. 1995; 113:1009-1016.
Clinical Ophthalmology

\section{Publish your work in this journal}

Clinical Ophthalmology is an international, peer-reviewed journal covering all subspecialties within ophthalmology. Key topics include: Optometry; Visual science; Pharmacology and drug therapy in eye diseases; Basic Sciences; Primary and Secondary eye care; Patient Safety and Quality of Care Improvements. This journal is indexed on Submit your manuscript here: http://www.dovepress.com/clinical-ophthalmology-journal

\section{Dovepress}

PubMed Central and CAS, and is the official journal of The Society of Clinical Ophthalmology (SCO). The manuscript management system is completely online and includes a very quick and fair peer-review system, which is all easy to use. Visit http://www.dovepress.com/ testimonials.php to read real quotes from published authors. 